\title{
Therapy with Siblings in Reorganizing Families
}

\author{
Elinor B. Rosenberg
}

ABSTRACT: The loss of parenting figures through death, divorce, or other kinds of separation of ten leaves children without consistent parental support and with increased fears of abandonment. In the natural cycle, siblings can maintain almost lifelong relationships and therefore are in a position to offer each other a significant support system over an extended period of time. We have found that work with sibling subgroups can help children to resolve their individual and shared conflicts as well as to remove interferences to mutually supportive relationships. Illustrative cases are presented and treatment guidelines offered.

Clinicians are becoming increasingly aware of the sibling subgroup as a powerful system within families. An early clinical impression is that sibling relationships vary through developmental stages of the life cycle. These relationships adapt to the differing needs of early and middle childhood, adolescence, adulthood and later life often then without living parents.

Over the past few years, some of us at the Youth Services Outpatient Clinic have worked intensively with sibling groups. In a number of cases, after a full diagnostic work-up of individual children and their families was completed, the decision was made to treat the sibling group separately. It was thought that these brothers and sisters had something special to offer each other which could be optimally developed if they were seen together without a parent present. The particular therapeutic goals in each case were different

Elinor B. Rosenberg A.C.S.W. is affiliated with the Dept. of Psychiatry, University of Michigan Medical Center. Reprint requests should be addressed to the au thor at the University of Michigan Medical Center, Ann Arbor, MI 48109.

An earlier version of this paper was presented at the National Conference of the American Association of Psychiatric Services for Children, November 1977, in Washington, D.C. Ms Rosenberg is grateful to Harvey Falit, M.D., and Fady Hajal, M.D., for their encouragement and support of this work. 
but the general thrust was toward enabling these siblings to help each other.

Looking back over the cases, we noticed that most of the sibling groups treated in this manner were from reorganizing families - that is, families that had lost at least one of their members and were reorganizing into a new family unit. This raises the hypothesis that there is some quality or characteristic of the reorganizing family that led the diagnostician to lean in the direction of focusing on the sibling subgroup. The result of these treatment efforts provides interesting clinical evidence to complement the current literature (Bank \& Kahn, 1975; Pollock, 1978), which suggests that the sibling group is a powerful and overlooked subsystem within families.

\section{REVIEW OF LITERATURE}

A primary function parents perform for their children is to provide an atmosphere of safety and security. Khan (1963), calls this a "protective shield," the precise qualities of which will vary with the differing developmental stages of child hood. He views this shield as an essential parental function over the whole course of a child's development where the child continues to need an auxilliary ego to support his immature and unstable ego functions. When the quality of parenting has been sufficient and conditions favorable, according to Kohut (1968), the child develops an infantile idealized image of the parents which is gradually tamed through a series of small disappointments.

Sometimes, however, parents are unable to provide this atmosphere of safety, and forces from within or outside the family prevail to produce an experience of trauma for the children. One such breach of the protective shield is through separation or loss of a parent or parents. Thus, in instances of death, illness, divorce, or other kinds of parental loss, the child often experiences a traumatic disappointment in the admired adult, and the childlike notion that the parents will always be together or at least one parent always available to serve as protector is shattered.

Despite highlighted differences of opinion in the psychoanalytic literature (Wolfenstein, 1966), there is almost unanimous concensus that the way children deal with loss is markedly different from adults. Since the child's ego cannot sustain prolonged grief, mechanisms in various combination defend against object loss. Substitution, denial, and repression soon take over and ward off bereavement. Given the knowledge of the kind of responses 
children tend to have to the loss of a significant object, it is useful to clinicians to examine the natural recuperative powers of the child as well as to explore potential therapeutic resources.

In Families of the Slums, Minuchin et al. (1967), has made an extensive study of families in which loss of parents' protective functions are common. They note that in those families where parents are unable to respond to children's physical and emotional needs, there is a natural gravitation of siblings toward each other in order to achieve some anchoring. Siblings then look to each other for reflected appraisal, guidance, control, and direction in terms of coping with the familial and outside world. They report that the sibling subgroup can become organized into a structure which sometimes functions with a predominant cohesive theme, and give examples of subgroups which serve as socializers, interpreters, a moralistic pack, and a rescue squad. Thus, they conclude that in disorganized families where parents relinquish executive functions, the unsatisfied needs of a child exert a pull that is responded to by siblings as a separate subsystem.

Bank and Kahn (1975) have explored these issues further in their paper "Sisterhood-brotherhood is powerful." They indicate that minimal research has been done in this area, with sibling studies performed primarily in terms of birth order and sex and its influence on personality development. Expanding on Minuchin et al.'s work on siblings, Bank and Kahn describe the sibling subgroup as an autonomous system which is obscured in the presence of the parents. They identified sibling functions as: (1) identification and differentiation, (2) mutual regulation, (3) direct services, and (4) dealing with parents through coalitions, joining against parents, telling secrets and tattling, translating functions, and pioneering. They note that loss of a sibling by death or through a move from the home produces a structured change in the family, though siblings continue to influence each other even when physically distant or without much direct communication. They suggest a number of therapeutic interventions with sibling subgroups, such as using siblings as consultants to individual treatment and holding sibling meetings.

Observations of the natural phenomenon of unprotected siblings turning toward each other suggest the operation of the ego defense mechanism of "substitution," referred to earlier. But cohesion and cathecting each other does not mean siblings are spontaneously and naturally helpful toward each other, even in times of trouble. It seems just as likely that a child's individual needs and/or intrapsychic conflicts would make competition characterize his relationships with siblings. The therapist thus faces a clinical decision as to 
when to support differences (perhaps even separate siblings), and when to support the alliances and mutuality within the group. The following cases illustrate such issues.

\section{CASE ILLUSTRATIONS}

\section{The Harris Family: A Case of Child Abuse}

This family included Mr. and Mrs. H., a son, and three daughters and was characterized by severe problems, including child abuse. By the time the fourth child was born, the parents were incapable of attending to most basic needs of their children. The eldest son, David, took on much of the responsibility for himself and his sisters. He received little physical abuse but his mother abused the girls, both physically and sexually.

One evening when David was 6, Karen 5, Cathy 4, and Susan 1 year old, Mr. and Mrs. H. had an argument and Mr. H. left the home. David allegedly tattled on Karen for taking a cookie thus provoking his mother's rage. Mother beat Karen and pushed her down a flight of stairs, causing fatal injuries. Mrs. H. was removed from the home and committed to a State Hospital where she remained for 5 years. The surviving children were placed in the care of their maternal grandfather and step-grandmother. Later, mother's release from the hospital and her request for unsupervised visiting privileges coincided with the news that the step-grandmother-the primary caretaking figure - had terminal cancer. The major figures in the children's life at this point included a previously abusing mother, a dying step-grandmother, and a periodically psychotic grandfather. There were no other family resources.

In the course of custody evaluation requested by the court, we ${ }^{*}$ saw the three children individually, as well as in a group, in order to assess the interpersonal dynamics. It became apparent that two predominant forces were at work within the subgroup. The first force was the children's need to reenact the trauma of their lives while colluding with each other to maintain prescribed roles. David, now 13, provoked anger and punishment particularly from Cathy ( 11 years old), whereas Cathy presented herself as the victim needing protection. Very subtly, however, she encouraged David's victimizing her and enjoyed getting him into trouble. Through all of this, Susan isolated herself in a very infantile, dependent manner as if she were still in her crib disassociated from the surrounding violence. The collusion between the three was remarkable in the way they helped each other maintain their roles of provoker, victim, and innocent baby. The second force operating was the children's recognition of their unique relationship to

\footnotetext{
* The author was a member of different cotherapy teams in each of the cases presented. The pronoun "we" will thus be based on a convenience
} 
each other as survivors and the enormous support provided by that uniqueness. When seen together, one could not help but be impressed by the strong bonds that existed between them. In most significant ways, it was "the three of them against the world."

We began seeing the three $\mathrm{H}$. children together, weekly. They became increasingly expressive about their problems at home, namely, the conflicts between the grandparents which produced in them fears of abandonment and anger at adults for not adequately protecting them. As they reenacted their special roles, we began labeling and acknowledging them. What emerged was the fact that David paid for his specialness as a boy (his nonabused status), with isolation, loneliness, and incredible guilt. We came to refer to these as his "oddball" feelings. We noted how Cathy liked to provoke David to harass her and how Susan liked to remain a babyliterally sucking on a doll's bottle during some of the sessions. We also talked about Karen and her place in the family. It was clear that all three children shared survivor's guilt and the need to idealize the lost object. In one session, Cathy expressed her long-termed resentment toward David-not for not interfering with her mother's abuse of her, but for laughing at her when she was being hurt. What she called a laugh was the giddy shriek we had all heard in previous treatment sessions when David felt anxious and scared. With the recognition that it was terror rather than ridicule that was being expressed, Cathy began making some tentative overtures toward David - showing the beginnings of understanding and forgiveness.

As time went on, the group interactions began to change. David made it clear he no longer wanted to be the "oddball"; he was also unwilling to put up with Cathy's constant blame, and he sought help in moving into the group. Susan began giving up her babyish ways and became clearly allied with Cathy, who served both as big sister and protective mother. Both girls struggled with their female identification. They experimented with roles, frequently asking the female cotherapist to play mother for them and requesting support for their own potential as mothers. Through both play and talk, they struggled with their wish to grow up and be good and "ordinary" and the underlying fear and belief that they, too, would ultimately become abusive.

When grandmother's physical condition began to deteriorate, 9 months into the treatment, the tension in the group increased. All three children expressed anger at the therapists for not being able to save grandmother and thus provide them with continued protection. In the process of working this through, they gave up a fantasy they had been nurturing: that the therapist would adopt them. In anticipating further placement, they began to express their common wish to stay together. Grandmother's death was followed by grandfather's severe deterioration leading him to resist all social and legal efforts to help provide for the children. Evidence of abuse and neglect finally precipitated their removal from the home. Staff descriptions of their behavior at the local youth home suggested mutually supportive roles - each serving different purposes at different times - and 
a marked sense of unity as the three children "stuck together" to face common struggles.

\section{The Browns: A Family of Divorce}

Mrs. B., a divorced mother, had referred two of her six children, Sally and Jim, for psychiatric evaluation. Jim, age 8 , had a recent intensification of long-standing problems of oppositional behavior. Sally, age 13, was reported to be withdrawn and depressed. In addition, Mrs. B. was feeling unable to deal with the hostility and chaos in her home since the marital separation four years before. Robert, age 15 , had been placed with his father 6 months prior to the referral because of behavioral difficulties at home, and Mrs. B. feared she would become as helpless with her remaining children as she had become with Robert. Living at home now were Mrs. B. (41), Cheryl (17), Sally (13), Jim (8), Richard (7), and Arlene (6 years).

In addition to individual interviews with the referred children, a diagnostic family session was held. In this session, Cheryl, the family spokesperson, complained of her mother's lack of effectiveness and commitment. When mother had returned to work, many of her responsibilities fell on Cheryl herself. Now that she was preparing to leave for college, Sally was next in line to assume these responsibilities. Sally, looking very guilty, indicated she was not willing to help.

Unable to manage the family herself, Mrs. B. allowed Cheryl to become a child with parental responsibilities, acting as if she were her mother's new husband. This union, however, was frought with the struggles born out of the generational differences. Cheryl's plan to leave for college threatened a new loss in the family and a vacant parental role which Sally was loathe to fill. The younger children were about to lose another significant parental figure. Mrs. B. was once again blamed by all the children, particularly Jim, as he most clearly expressed the rage at his mother. It became clear that Sally and Jim were the symptom bearers in the family's struggle to deal with the break up of the marital pair and its sequellae.

Mother had reported a long history of squabbling and distance between the two girls, and her impression was that it was primarily Cheryl who rejected Sally's overtures toward closeness. Cheryl was indeed critical of Sally, whom she considered lazy. She seemed to feel that despite her own exploitation, Sally ought to fill in when she left. Sally partially accepted this too, and was thus immobilized in guilt and depression. The two sisters had many commonalities, however. They were both attached to the old family, and shared happy memories as well as nightmares of the tension that had occurred. Both girls were significantly overweight, paid little attention to their own appearance, and were united in the rejection of heterosexual relationships and the notion of ever marrying and having a family.

In the treatment sessions, we focused on their commonalities. We relived the break up of the family and mourned the loss of the original family group. Cheryl was given permission for the resentment of her parental role, 
ELINOR B. ROSENBERG

and Sally was concomitantly given permission not to fill it. Disappointment and distrust of men was also addressed both through historical material, and more subtly, through the cotherapy relationship. On this issue the therapeutic thrust was: you have had a bad experience, but this does not necessarily mean that half the world's population must be rejected.

We began to see increased interactions between the two girls. They arranged transportation for the sessions together and later reported common outside activities. With the consolidation of the relationship came a request from the girls that mother attend the sessions every other week. Their agenda was to work out some issues of authority (privileges, responsibilities, school plans, etc.), and make sure that mother understood how they felt about things. These sessions were characterized by the girls' mutual support, as each struggled for autonomy on her own level.

The sessions were terminated after 10 months when Cheryl went off to college. Follow-up reports indicate that both girls have lost weight, are taking good care of themselves and have a full complement of male and female friends. Sally occasionally visits her sister at college and mother feels they are now friends who help sustain each other through the continuing trials of the one-parent family situation.

\section{The Johnsons: A Combined Family}

The Johnson's marriage was the second for each parent and the family included "his" three boys (ages 17, 16, and 15), "her" two girls (ages 14 and 13), and "their" 15-month-old daughter. They came to the clinic for help several weeks after the accidental death of Mr. J.'s 15-year-old son. Longstanding problems of marital difficulties, parent-child tensions, and intense sibling conflicts were exacerbated by the death of a child and the significance it had to each family member. A frequent result of conflict in this family was to threaten separation or a retreat to the original family groupings. When this happened, the children expressed fears of abandonment and concern about adequate protection.

The family was first taken into treatment all together with focus primarily on the death of Mr. J.'s son, Michael, and the impact his loss was having on all the family members. Guilt was experienced by each member while blame was lobbed around the room. As these issues were dealt with and seemed more manageable, the therapist decided to attempt a structural intervention by bringing about a division of the family along generational lines rather than original family lines and we began seeing the parents and the children separately. One technical problem we faced was the inclusion of the 15-month-old "ours" child. Her presence at the diagnostic sessions seemed essential.

We could observe the ways in which she threaded the family together, as she represented the new life. We could also see how child-care responsibilities were delegated. Given her young age and needs, however, she frequently became a distraction to the work at hand, and for this reason we 
decided not to include her regularly in the sibling sessions. Rather, we asked that she attend periodically to help us assess the current state of her place in the family group.

The teenage children-Mark (17), Scott (16), Jennifer (14), and Mary (13 years) welcomed the opportunity to meet together. Each felt children of the other sex were favored by the parents. Sparks flew as they complained about the unfairness at home. What was also apparent was that the sparks represented other kinds of passion as well. These teenage boys and girls were having a difficult time with the attraction they felt toward each other and countered their positive (sexual-affectionate), feelings with negative (bickering), ones. They all seemed to have decided that it was safer to fight than to love. The therapists commented on how hard it must be for boys and girls who could be dating each other to be living in the same house. We were then informed by the teenagers that they felt it was impossible to be like brothers and sisters when there were no blood ties. There seemed to be great relief in uncovering this difficulty and tension between them began to diminish.

Issues of integration and loss were rekindled by Mark's move to his grandmother's house nearby and his stated wish to leave the sessions. Everyone at first agreed that it did not matter much because Mark was seldom at home anyway. The therapist doubted that it did not matter much and pointed out that Michael's loss mattered plenty to everyone, though it had been very hard to talk about. Mark expressed reemerging loyalty conflicts, old resentments, and fears. Under stress, it appeared that going back to the old family became an emotional option. All the children felt angry at father for seeming to do so little to try to keep Mark with them. Scott expressed his feelings of loneliness at having now lost two brothers and thought that perhaps he, too, should move out. The therapists noted how the pattern of abandonment and extrusion was a family style and what little experience any of them had with resolving a conflict rather than leaving it. The children wanted this to be different and essentially told each other they wanted everybody in. As time went on, we saw more evidence of closeness between the siblings and stepsiblings as they shared confidences and showed mutual trust. Scott made a clear commitment to stay in the family. For the first time, we began to see alliances formed across original family lines. We also saw the sibling group in alliance against both parents on issues (such as bedtime, privileges, and chores), which would naturally divide along generational boundaries.

Relationships with steparents became the next "subject." In one session, the girls complained vigorously about their ugly and horrible stepfather. The affect with which they described his repulsiveness suggested a thinly disguised attraction. This was addressed in the same manner as the therapists had dealt with their attraction to their stepbrothers: "It's hard to deal with the confusing, exciting feelings of becoming a young woman when you live with men you are not related to." Once again the labeling of the problem seemed to have a therapeutic effect. Sparks between the stepsibs and between the stepparents and children seemed to subside. Scott 
told us one day, "Jennifer doesn't bother me anymore." In this way, the children were able to anchor themselves with each other while they continued to scramble for emotional supplies, struggle with their emerging sexuality, and deal with ongoing conflicts related to divorce and remarriage.

\section{DISCUSSION}

The case material presented suggests that destructive forces within a sibling group can be reworked so that adaptive mechanisms become more accessible. The Harris family (case of abuse), offers the most dramatic illustration of this process. Since the siblings had experienced and survived severe trauma together, the possiblity of their working through trauma together seemed promising. Seeing the children together without parents or parent substitutes maximized the opportunity to focus on their shared view of the world as a frightening one and to focus on their relationships to each other. The therapists could observe their relationships directly and offer alternate ways of understanding and behaving which would ultimately be more adaptive for all of them. The development of a mutually supportive system was a significant means of physical and emotional survival, particularly as they faced their mother's reappearance and the terminal illness of their grandmother. Technically, one major problem was working with grandfather to block him from interfering with this process. In this case, a different therapist worked with the grandparents focusing on their individual, marital, and parental concerns thus separating these from the children's struggles. A second problem was maintaining a therapeutic role rather than filling a tragically vacant parent position. The cotherapists supported each other with this approach.

In some families, there is more than one subgroup of siblings. In the Brown (one-parent) family, for example, it became apparent that there were two subgroups of children - the "older kids" and the "younger kids," each group having different developmental tasks. In this case, it was our judgment that seeing all the siblings together would be countertherapeutic because the primary task of the younger ones was integration within the modified family unit, whereas the primary task of the older ones was separation and individuation. Our goal in seeing the older girls together was to assist them both in their strivings toward autonomy and to help them deal with their conflicts around the assumption of the parental role. The goal was to enable the eldest to leave home with less conflict and to 
give the younger one permission not to fill her sister's quasi-parental place. Working with the two girls together without their mother diminished the rivalry issue and allowed them to disentangle themselves from the parenting functions. Once this was completed, they were free to invite mother into their sessions without fear of becoming reinvolved in that struggle. The presence of cotherapists with the girls offered the opportunity to observe how they related differentially to men and women and helped them identify their resistance to heterosexual relationships. It also allowed for a "corrective emotional experience" in observing a man and woman who sometimes disagreed but continued to work out problems together. Technically, our biggest problem was in not becoming surrogate parents. Particularly in a period when the girls were feeling critical of their mother (each for her own reason), there was ample opportunity to fall into this role. Retrospectively, it seems that we were probably seen as extraparental adults-like friends' "better" parents, so common for separating adolescents.

In working with combined families, it is of ten a goal to help two families merge into one and therapeutic efforts are frequently geared toward reinforcing generational rather than original family boundaries. In the Johnson family, the advantages of working with the sibling subgroup emerged serendipitously as we attempted to reinforce the generational boundaries. One result was that the sibling group was able to reverse the family pattern of abandonment and extrusion long before the parents were able to work through their own fears of intimacy and permanency.

From experiences such as the above, it seems that the sibling group therapy modality has a number of indications as well as counterindications and involves some technical problems. Focus on the sibling group is particularly indicated when parents are unavailable or inadequate and the children have the capacity (through age and circumstance), to provide emotional "anchoring" as well as other mutually supportive functions. The length of time that siblings need to look to each other for such support will depend on the capacities of the parents or the provision of substitute adults who can become psychological parents. Some children may look back over their early years and say "we [siblings] really helped raise each other."

A second circumstance in which focus on the sibling group seems indicated is when (in any kind of family organization) we see a sibling relationship that is a developmental interference which is exacerbated by the presence of one or both parents. Here, allowing the siblings to meet without parents, offers the best opportunity to detriangulate the struggles and develop generationally based alliances. 
Sibling group therapy is counterindicated when a study of the family structure suggests that parenting functions are potentially adequate but overly rigid generational boundaries prevent an effective provision of these functions. Although a therapist could help the children develop more effective ways of seeking out their parents, grouping them apart in itself reinforces the boundaries and thus seems counterproductive.

A primary concern in working with sibling groups is the problem of dealing with parents. When the decision for sibling grouping is made, the parent's response is frequently: "Good, I'm sure they will talk more freely without us there." Underlying this statement is often concern about what the children will say and their possible collusion against the parents. Sometimes there is a fear and/or wish that the therapists will take over the parenting roles. For these reasons, we found it essential to maintain contact with parents in some manner. There are innumerable options depending on the clinical issues but involvement with the parental unit is essential to the success of work with the sibling groups.

Separating sibling groups in family therapy raises the issue of confidentiality. It is particularly salient when there is a flexibility in subgroup membership. Through trial and error, we found that it was best not to change the basic guideline in family therapy and that the family must trust the judgment of the therapist as to the usefulness of sharing information or impressions and not to make any promises of confidentiality. Such promises are sometimes requested by one or more family members and usually serve to support unadaptive forces within the group by tying the therapist's hands. Instead, the wise therapist establishes a situation where he or she has the freedom to make the most effective interventions.

One advantage of family work is that the therapist is an added force to the existing family. A technical problem of a therapist or cotherapists with a sibling group is the way in which the group simulates a "real" family. Particularly when there is a vacant position (as in one-parent or orphaned families), there is a strong pull toward the therapist to fill these positions. Ultimately, this will work against real changes in the family system and terminate with disappointment and loss. In treating sibling groups, then, the most effective posture is in maintaining a coaching and enabling role and steering clear of direct parenting functions.

\section{CONCLUSION}

Children need parental figures to meet their ongoing developmental needs. We have shown that when such parenting is unavailable or 
inadequate, siblings can sometimes capitalize on their common circumstances to provide essential emotional functions for each other on a long- or short-term basis.

Our choice of the sibling group is based not on a new theory or new techniques, but rather on an increased awareness of the positive aspects of sibling relationships. Given that siblings are likely to outlive their parents and thus be in a position to provide lifelong relationships, sibling subgroups appear to be a highly overlooked resource and an excellent therapeutic investment. Our task now is to learn more about the functions of siblings and sibling subgroups as they move through the various developmental stages of the life cycle and to find new ways of maximizing the usefulness of the natural bonds between brothers and sisters.

\section{REFERENCES}

Bank, S., \& Kahn, M. Sisterhood-brotherhood is powerful: Sibling subsystems and family therapy. Family Process, 1975, 14(3), 311-337.

Khan, M. The concept of cumulative trauma. Psychoanalytic Study of the Child, 1963, 18, 286-306.

Kohut, $H$. The psychoanalytic treatment of narcissistic personality disorders. Psychoanalytic Study of the Child, 1968, 23, 86-113.

Minuchin, S. et al. Families of the slums. New York: Basic Books, 1967.

Pollock, G. On siblings, childhood sibling loss, and creativity. The Annual of Psychoanalysis, 1978, 6, 443-481.

Wolfenstein, M. How is mourning possible? Psychoanalytic Study of the Child, 1966, 21, 93-123. 